\title{
Germanica
}

\section{Hélène Pierrakos, L'ardeur et la mélancolie. Voyage en musique allemande}

Paris, Fayard, « Les chemins de la musique », 2015, 200 p., ISBN

978-2-213-68174-0

Irène Cagneau

\section{CpenEdition}

\section{Journals}

Édition électronique

URL : http://journals.openedition.org/germanica/3222

DOI : $10.4000 /$ germanica.3222

ISSN : 2107-0784

Éditeur

Université de Lille

Édition imprimée

Date de publication : 30 septembre 2016

Pagination : 227-229

ISBN : 9782913857377

ISSN : 0984-2632

Référence électronique

Irène Cagneau, «Hélène Pierrakos, L'ardeur et la mélancolie. Voyage en musique allemande »,

Germanica [En ligne], 58 | 2016, mis en ligne le 30 septembre 2016, consulté le 06 octobre 2020. URL http://journals.openedition.org/germanica/3222 ; DOI : https://doi.org/10.4000/germanica.3222

(c) Tous droits réservés 


\section{Compte rendu de lecture}

Hélène Pierrakos : L'ardeur et la mélancolie. Voyage en musique allemande, Paris, Fayard, "Les chemins de la musique », 2015, 200 p., ISBN 978-2-213-68174-0.

Hélène Pierrakos ${ }^{1}$ invite ici le lecteur à un " voyage en musique allemande », placé sous le signe de l'ardeur et de la mélancolie, deux notions fédératrices qu'elle définit elle-même comme un " alliage chimique ou un parfum, dans toute la variété de ses dosages et de ses proportions » (p. 97), dont les nuances subtiles se révèlent progressivement au fil de la lecture.

Composé de neuf chapitres, qui sont autant d'étapes au cours de ce voyage, le livre d'H. Pierrakos doit être lu non pas comme un guide conventionnel ou un simple mode d'emploi, mais bien davantage comme le « relevé d'une série d'impressions de voyage - ou même de désirs de voyage » (p. 12), un journal de bord musical, assurément subjectif, qui incite le lecteur mélomane à l'écoute, à la réflexion et au rêve. Si l'auteur évoque ici des impressions, le développement de son raisonnement est tout sauf impressionniste. La pensée est structurée, nourrie d'exemples issus de multiples œuvres vocales et instrumentales, l'écriture est claire et précise, le ton est toujours juste et les références aux œuvres sont mentionnées avec le plus grand $\operatorname{soin}^{2}$. Une sélection bibliographique et un index complètent très utilement l'ouvrage.

1. - Hélène Pierrakos a été productrice à France Musique et rédactrice à la Philharmonie Luxembourg. Elle anime actuellement l'émission La malle à musiques sur Fréquence protestante.

2. - On appréciera par exemple que les titres des œuvres, les citations ou encore les textes des lieder soient toujours rédigés en allemand, accompagnés de leur traduction française.

GERMANICA, 2016, LVIII, pp. 227 à 229. 
Parmi les chapitres proposés, les plus séduisants pour un germaniste sont sans doute ceux qu'H. Pierrakos consacre à la «poétique du pas » (II), aux « mécanismes et ressassements » (III), au « folklore rêvé » (IV) et à l'« idylle d'azur » (V). Au-delà des styles et des époques, l'auteur a en effet l'art de souligner de façon convaincante les liens structurels, thématiques et esthétiques, sinon même intuitifs, qui peuvent s'établir entre des œuvres parfois très différentes. À travers la figure du pas (qui évoque d'ailleurs la notion complexe de Takt en allemand), se révèle toute une "rhétorique sonore » (p. 21) de la musique allemande, une « force expressive de la pulsation » (p. 24) qui se déploie aussi bien dans les chorals de Bach (tel le prélude de Ich ruf zu Dir, Herr Jesu Christ BWV 639) que dans le Voyage d'hiver de Schubert ou la Nuit transfigurée de Schoenberg. Le pas, en tant que «scansion» et « assise rythmique » (p. 24), peut alors figurer tour à tour la marche du pèlerin, les piliers du chant d'église, l'élévation, l'illumination, mais aussi l'immobilité, la fragilité ou encore l'errance solitaire du voyageur. Ces réflexions sur la « poétique du pas » dans la musique allemande conduisent naturellement $\mathrm{H}$. Pierrakos à s'interroger sur sa « radicalisation en mécanisme » (p. 34). Dans le chapitre III, elle convoque ainsi Beethoven, Mozart, Bach et Schubert afin de mettre en lumière la puissance de la «mécanique souterraine » (p. 42) qui sous-tend les œuvres germaniques. L'auteur consacre par exemple un développement détaillé à la «force motorique » (p. 43) qui anime la musique de Schubert et en montre avec finesse tous les effets de répétition, de réitération et de renchérissement, que ce soit dans les Impromptus et Moments musicaux, les symphonies ou les cycles Voyage d'hiver et La Belle Meunière. À cet égard, le lecteur germaniste ne pourra qu'apprécier les liens pertinents qu'H. Pierrakos prend le temps d'établir entre le texte allemand des lieder et leur mise en musique.

Le chapitre IV s'intéresse à l'influence marquée du folklore dans la musique allemande et en souligne toute la richesse et la diversité, en particulier chez des compositeurs comme Schubert, Mendelssohn, Schumann, Brahms et Mahler, pour n'en citer que quelques-uns. $\mathrm{H}$. Pierrakos montre que, contrairement à la France, où l'empreinte du folklore s'est progressivement estompée au cours du XIX ${ }^{\mathrm{e}}$ siècle, le « va-et-vient du savant et du populaire » (p. 56) n'a jamais cessé en Allemagne, offrant ainsi un terreau fertile aux compositeurs. Qu'il s'agisse de figures codifiées, de citations conventionnelles, d'allusions teintées d'ironie ou de résurgences soudaines au détour d'une phrase musicale, "l'ailleurs rêvé dans la musique d'inspiration populaire » (p. 75) constitue ainsi un élément constitutif de l'identité de la musique allemande. Le titre du chapitre V, «l'idylle d'azur », est quant à lui fort bien choisi puisqu'il évoque immédiatement le Kennst du das Land... goethéen et sa mise en musique par Schumann, Schubert ou Wolf. Ici, H. 
Pierrakos nous fait voyager avec bonheur en Italie, puis en Grèce. Des « italianismes musicaux » (p. 85) à la quête de la «beauté primitive du monde grec antique » (p. 86), les œuvres de Mendelssohn, Liszt, Wolf, Schubert et Richard Strauss sont étudiées avec précision. On retiendra en particulier les développements détaillés que l'auteur consacre à la « poétique schubertienne » (p. 90), notamment à la mise en musique de Die Götter Griechenlands de Schiller.

Si les autres chapitres de cette étude suscitent également l'intérêt soutenu du lecteur, on peut regretter qu'H. Pierrakos s'éloigne parfois de sa démarche initiale, consistant à souligner la « connivence expressive » (p. 16) qui unit certaines œuvres au-delà de leurs spécificités formelles, et consacre des analyses trop approfondies à un compositeur en particulier. C'est par exemple le cas du huitième chapitre (« la pensée inquiète »), presque exclusivement dédié à Mahler ; la fin du chapitre (p. 163-178) fait ainsi davantage penser à une note de programme de concert qu'à une démonstration intégrée à la réflexion générale et se trouve ainsi en légère dissonance avec le reste de l'ouvrage.

Malgré ces quelques réserves, le livre d'H. Pierrakos se distingue par la clarté du raisonnement et la richesse de ses exemples. Dans sa préface, Rémy Stricker souligne que la grande qualité de l'auteur est de « donner à entendre » (p. 7), une expression que l'on peut comprendre comme une incitation à l'écoute, bien sûr, mais aussi comme une aide à la compréhension des œuvres. Outre cette qualité indéniable, H. Pierrakos a également le talent de nous «donner à voir ». À la fin de la lecture, ce ne sont pas seulement les œuvres de la musique allemande qui résonnent en nous (du lied le plus intime à la symphonie la plus majestueuse), ce sont également des images qui nous marquent de leur empreinte : les traces de pas dans la neige d'un voyageur solitaire et les gestes mécaniques d'un jeune soldat promis à une mort certaine, les paysages d'azur et les sommets alpestres, les sombres abîmes et les larmes du deuil. On ne peut donc que recommander au lecteur cette invitation au voyage qui propose un itinéraire original et stimulant au cœur des territoires de la musique allemande.

Irène Cagneau 
